\title{
INVESTIGACIONES
}

de HISTORIA ECONÓMICA

2006, otoño, número 6. Pp. 11 a 40

\section{La integración del reino nazarí de Granada en el espacio comercial europeo (siglos XIII-XV)}

\author{
The integration of the Nasrid kingdom of Granada \\ in the European commercial platform (13th-15th centuries)
}

\author{
ADELA FÁBREGAS GARCÍA \\ Universidad de Granada
}

\begin{abstract}
RESUMEN
La inclusión del reino nazarí de Granada en el entramado mercantil del Occidente bajomedieval resulta innegable atendiendo a ciertos indicadores: la presencia de diferentes comunidades mercantiles foráneas; la activación en su seno, por parte de las principales estirpes de negocios europeas, de técnicas financieras y mercantiles de gran calado; la apertura de sus puertos al tráfico marítimo internacional; y la colocación de artículos nazaríes en los principales mercados europeos. Todo ello se enmarca en un contexto de desarrollo económico generalizado de

Occidente, se traduce en una fuerte dinamización de la actividad comercial granadina, y revierte en una reorientación de la estructura socioeconómica del reino. Superado este planteamiento general de la situación, hasta el momento ha sido complicado determinar las pautas de la evolución de este fenómeno en el territorio nazarí. Pretendemos aprovechar la oportunidad que nos brinda una nueva y espléndida serie documental, la contabilidad privada de mercaderes genoveses activos en Granada entre 1435 y 1455, para iniciar un acercamiento a estos temas.
\end{abstract}

PALABRAS CLAVE: Reino de Granada, Redes comerciales, España medieval

Códigos JEL: N13, N43, N73, N93

\section{ABSTRACT}

There is no doubt about the presence of the Nasrid kingdom of Granada in the mercantile platform of Europe. Various indicators support that: different foreign mercantile communities worked in the area; the most important European races activated here sophisticated financial and mercantile technologies; the Nasrid ports were opened for the maritime international traffic; and lastly, Nasrid commodities could be found in the most important European markets. This integration of the Nasrid kingdom took place in a widespread context of economic development in Occident, generated a strong dinamization of the commercial activity and meant a reorientation of its socio-economic structure. Overcome this general approach, up to the moment however has been complex to identify the guidelines of that evolution. This research extensively based on a new and splendid data - the accounting deprived of Genovese merchants active in Granada between 1435 and 1455-, constituted a first approach to these topics.

KEYWORDS: Nasrid kingdom of Granada, Commercial networks, Medieval Spain

JEL Codes: N13, N43, N73, N93 


\section{Introducción. El desarrollo comercial de la Europa bajomedieval ${ }^{1}$}

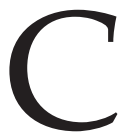

ómo y por qué el reino nazarí de Granada llegó a ser a finales de la Edad Media uno de los territorios más directamente implicados en la red comercial internacional que abarcaba todo el Occidente europeo, son temas tratados por otros autores en contextos más generales de análisis del Occidente bajomedie$\mathrm{val}^{2}$, o de observación de la propia realidad sociopolítica nazarí ${ }^{3}$. Lo cierto es que, sin entrar demasiado en un tema en el que debemos manifestar nuestro acuerdo con lo ya planteado por otros autores, sí parece claro que la realidad nazarí como entidad comercial se conforma mediante la confluencia de una serie de elementos concomitantes de naturaleza endógena y exógena. En otras palabras, esta orientación comercial de parte de la economía nazarí surge en un contexto general especialmente favorable a la potenciación comercial de los territorios situados en el extremo occidental del Mediterráneo, y se desarrolla merced a una singular predisposición del pequeño reino islámico a ampliar esta faceta, en la cual sus líderes parecen encontrar una garantía de supervivencia, no sólo económica sino, incluso, política.

El conocido "repliegue hacia Occidente" de las grandes potencias mercantiles europeas, que culmina con la apertura de las rutas de circunnavegación atlánticas y la consolidación del polo comercial bajomedieval, es resultado de un proceso iniciado en el siglo XII bajo la iniciativa de potencias como la genovesa, la pisana o la catalana. Desde luego, no son ajenas al mismo las crisis políticas y los reajustes en las relaciones entre las emergentes naciones comerciales europeas y las primitivas fuentes de aprovisionamiento de bienes de comercio levantinos, amén de otros factores, como la inadaptación misma de los esquemas socioeconómicos de Oriente a los requerimientos del nuevo sistema económico. Los esfuerzos de síntesis han llevado a otros investigadores a confeccionar un esquema-secuencia de lo sucedido, en el que tienen cabida acontecimientos y tendencias de desarrollo como los siguientes ${ }^{4}$ :

1) El tradicional motor comercial levantino pierde potencia, lastrado por los problemas políticos ligados a las conquistas turcas y las querellas sobre el reparto de zonas de influencia mantenidas por las grandes potencias mercantiles occidentales, Génova y Venecia, resueltas a favor de esta última.

[Fecha de recepción del original, enero de 2006. Versión definitiva, mayo de 2006]

1 El presente trabajo se ha desarrollado en el marco del proyecto de investigación "La ciudad y su territorio en época nazarí" (MCYT BHA2033-00743), cuyo investigador principal es Antonio Malpica Cuello. Agradezco, asimismo, a los evaluadores anónimos de Investigaciones de Historia Económica las sugerencias realizadas.

2 Heers (1961) y Pistarino (1987). Las principales líneas de estudio pueden consultarse en trabajos como los de Chiapa (1973), Simbula (2001) y Abulafia (2002).

Malpica (1999).

Abulafia (2002). 
2) Las pérdidas, sobre todo en el caso de Génova, se compensarán con la apertura de nuevas posibilidades en las riberas occidentales del Mediterráneo como áreas proveedoras y como mercados de consumo. A éstas se añadirán, más adelante, las islas atlánticas, territorios vírgenes aptos para producciones especializadas.

3) El declive económico del mundo islámico y la inadecuación de su estructura productiva a las nuevas realidades económicas favorecen el cambio de dirección de las corrientes de exportación, constituyéndose el mercado levantino en área de consumo en detrimento de su antigua faceta como espacio proveedor. Esto, lógicamente, puede suponer un fuerte impulso a la regeneración productiva de Occidente.

4) Además, los espacios occidentales manifiestan una tendencia a organizarse en áreas de especialización productiva, que a su vez activan y favorecen la expansión del comercio local y de los intercambios a corta y media distancia, lo cual supone un factor dinamizador de la economía de la zona.

5) Y todo ello, liderado por las potencias comerciales de la Cristiandad mediterránea europea (venecianos, genoveses, florentinos y catalanes, principalmente), afecta no sólo a sus propios territorios, sino que se traduce en un florecimiento económico general de Occidente, incluyendo los territorios musulmanes allí existentes. Sobre la pregunta de si la estrategia de la creación de un polo comercial en la Europa occidental como centro neurálgico del nuevo sistema de negocios es una elección circunstancial, tomada como única solución ante el previsible fin de los privilegios levantinos, o si en realidad forma parte de un plan más ambicioso, concebido con anterioridad y cuya siguiente fase tiene luz verde ahora, existen respuestas encontradas. En todo caso, se trate de un movimiento pendular o de una tendencia de dilatación progresiva, lo cierto es que el comercio internacional experimenta un desarrollo decisivo. Hasta tal punto es así, que se ha llegado a identificar el fenómeno que tiene lugar en los últimos siglos medievales como una revolución comercial, de consecuencias para el desarrollo económico de Occidente sólo comparables con las de la revolución industrial iniciada a finales del siglo XVIII ${ }^{5}$.

Esta relevante transformación de los sistemas económicos fue, obviamente, un proceso largo y complejo, que, como ya recordamos, se inició a partir del siglo XIII, e incluso antes, hacia mediados del XII, con la primera fase del despegue económico del Occidente feudal. Desde entonces, se suceden fases de activación comercial, materializadas en fórmulas como el famoso capitalismo mercantil, crisis de integración ${ }^{6}$ y relanzamientos que se dirigen inexorablemente hacia una convergencia social y económica identificada con el capitalismo.

5 Por ejemplo, Spufford (2002) presenta en estos términos su magnífica síntesis sobre el desarrollo comercial bajomedieval.

6 La famosa crisis del siglo XIV, de explicaciones múltiples y variadas, viene siendo interpretada últimamente como una crisis de integración de mercados. Véase Epstein (2000). 
El proceso de surgimiento de los fundamentos básicos del nuevo sistema capitalista es largo, su análisis complejo y, evidentemente, no es ésta la ocasión de profundizar en él. Se trata de uno de los pilares de la discusión historiográfica, que se mueve en torno a posturas antagónicas; unas enfocan el germen de la disolución feudal y de la evolución hacia el capitalismo como un conjunto de factores ajenos al sistema feudal7; otras, por el contrario, juzgan éstos consustanciales al mismo. En esta última corriente se ha subrayado la importancia del mercado, considerado finalmente como fenómeno endógeno del feudalismo ${ }^{8}$, a modo de principio disolvente de una sociedad de base fundamentalmente agraria, marcada por los ritmos de la economía campesina que definen la formación feudal. Por último, la investigación más reciente subraya el peso decisivo de los cambios que experimenta la estructura de la propiedad y la incidencia positiva que, sobre el desarrollo del sistema de comercio y mercado, tendrán las nuevas estructuras institucionales y su traducción en el proceso de centralización jurisdiccional ${ }^{9}$.

Independientemente de la centralidad que asuma la dinámica de mercado en el proceso de desarrollo económico de Occidente y de transición hacia el capitalismo, lo que resulta indiscutible es su papel como indicador de la marcha del proceso y como una de las vías de crecimiento del mismo. De hecho, es constante la atención que se le presta a la hora de identificar y analizar las sucesivas fases de desarrollo y contracción que, a partir de su impulso inicial, fue asumiendo la dinámica comercial durante los últimos siglos medievales. Otra cosa es identificar los caracteres de las diversas fases de aceleración y desaceleración del proceso. Tampoco este tema está exento de polémicas y de revisiones periódicas. El comercio genera, efectivamente, una primera forma de capitalismo, el capitalismo comercial, basado en el sistema de comercio de tránsito (carrying trade), desarrollado a partir del siglo XIII por las repúblicas comerciales italianas ${ }^{10}$ y que, en realidad, no puede ser considerado más que como una fase de "maduración organizativa" del sistema económico meridional11. En esta primera revolución comercial proliferan mercaderes cuyo objetivo final es conseguir un mero enriquecimiento a través de la especulación, pero cuya acción en ningún momento trascenderá del ámbito estrictamente mercantil, ni revertirá en una variación del sistema de producción industrial o agrícola.

7 Las interpretaciones maltusianas, defendidas por historiadores como Postan, son las tesis más representativas de esta corriente, hegemónicas durante mucho tiempo en el discurso historiográfico.

$8 \quad$ Hilton (1988). Brenner (1988), empero, considera ajenos en todo momento a la formación feudal el mercado y la dinámica comercial, atendiendo exclusivamente a los aspectos agrarios del sistema.

$9 \quad$ Epstein (2000), pp. 38-72.

10 Una buena caracterización del sistema vigente en estos siglos bajomedievales, basada en el análisis del sistema desarrollado por las repúblicas marítimas italianas, puede verse en Manca (1987).

$11 \quad$ Iradiel (1986), p. 66. 
Otro caso emblemático de cuanto venimos diciendo es el tratamiento que se ha prestado al análisis de la famosa crisis del siglo XIV, percibida, entre tantas otras interpretaciones, como una fase de contracción o como una crisis de crecimiento, de integración, de los nacientes sistemas de mercados occidentales ${ }^{12}$. Desde luego, es cada vez más evidente su importancia en la conformación y afianzamiento del nuevo sistema de comercio internacional que, una vez superada la crisis, se constituirá a ritmos y marchas desiguales en el moderno sistema mundial. Precisamente la falta de sincronía con que se incorporan los cambios en ese sentido, ha incitado a interpretar aquél, durante mucho tiempo, como un sistema basado en relaciones de subordinación y dependencia plasmadas en la imagen económica de centro-periferia. Hace ya algún tiempo se empezaron a señalar las contradicciones de esta definición ${ }^{13}$, siendo en la actualidad cada vez más numerosos y más certeros los estudios que plantean la situación en términos de un desarrollo polinuclear, basado en la definición de espacios autónomos cada vez mejor integrados como anclajes de un sistema de comercio constituido por redes de intercambio ${ }^{14}$. Éste es precisamente el marco de trabajo en el que pretendemos ubicar al territorio nazarí. Su particular adscripción a una formación social islámica, ajena, por tanto, a los principios propulsores del desarrollo de Occidente, no le impide adherirse nítidamente a las tendencias de crecimiento del área. En nuestra opinión, es preciso estudiar desde qué posición participa el reino nazarí en todo ello y elucidar los términos concretos de su inclusión. Lo que sigue es un primer intento de acercamiento, seguramente incompleto, a estas cuestiones.

\section{Un reino abocado al comercio}

La base económica y la situación geopolítica resultan muy favorables a la inclusión del reino nazarí en el despegue comercial descrito, que involucra a toda la región. Su ubicación en el arco mediterráneo de la península vecino al estrecho de Gibraltar le confiere un valor añadido como territorio de tránsito de una de las grandes arterias del espacio comercial europeo, el cual viene a sumarse a las tendencias generales de

\footnotetext{
Epstein (2000).

Un buen ejemplo de ello en Iradiel (1986).

Hilario Casado está investigando, desde esta clave, el ilustrativo caso de los mercaderes y mercados castellanos, contribuyendo a redimensionar y enfocar de manera mucho más nítida la presencia castellana en el entramado comercial europeo. Queremos agradecerle su generosidad por habernos permitido consultar trabajos aún no publicados que constituyen aportaciones fundamentales (Casado, en prensa a, y en pren$\mathrm{sa}$ ).
} 
desarrollo antes citadas. Éstas encuentran en el territorio nazarí unas condiciones productivas favorables, apoyadas en una tradición tecnológica y agrícola muy consolidada, que facilita la obtención de excedentes aptos para su comercialización ${ }^{15}$. La generalización en Al-Andalus de la agricultura de regadío a partir de su introducción de manos de la cultura árabe, supone no sólo el aumento de la productividad agrícola, sino la adopción de prácticas y cultivos desconocidos en Occidente, algunos de los cuales, caso de la caña de azúcar, la seda o el algodón, resultan particularmente aptos para la especulación comercial y, de hecho, se convierten en puntales, entre otros, del sistema mercantil bajomedieval. Se trata de artículos muy apreciados, conseguidos hasta entonces en las bases de aprovisionamiento levantinas, que a partir de ahora se buscarán en las zonas del Occidente islámico de características medioambientales igualmente aptas para su obtención. Sin embargo, tales territorios no se convierten por ello, ni mucho menos, en espacios de especialización agrícola dedicados a la producción de bienes de comercio. La base social que sustenta el sistema socioeconómico nazarí, pese a la descomposición que muestra frente a la primitiva formación andalusí, supone, en su propia dinámica interna, un freno o mecanismo de ralentización indiscutible de tales tendencias ${ }^{16}$.

Por lo demás, frente a las reticencias que pudiese despertar la asimilación a la órbita comercial cristiana de un territorio islámico como el reino nazarí, cabe recordar las circunstancias que rodearon su nacimiento y jalonaron su existencia. Éste, el último reducto islámico en la península Ibérica, nace a partir de una alianza con Castilla, con cierto matiz vasallático, al menos al principio, lo que le obliga a mantener un juego de equilibrios internos y externos básico para su supervivencia. Su realidad está marcada por elevados niveles de dependencia política y económica respecto al exterior. La Castilla feudal y los poderes musulmanes norteafricanos constituyen los dos polos de atracción y presión alternativa, entre los cuales el equilibrio dependerá de las sucesivas tácticas de alineamiento o acercamiento a otros poderes regionales. De hecho, la posición estratégica del reino nazarí para un Occidente mediterráneo crecientemente interesado en el mundo atlántico y en la vía marítima de conexión entre la Europa meridional y la septentrional, propicia que, en un momento determinado, Granada elija como medio de supervivencia la opción comercial que otras potencias mediterráneas, interesadas en incluir su territorio en su órbita de influencia, ofrecen a cambio de su apoyo, a veces incluso militar.

Watson (1998) y Malpica (1999).

Malpica y Fábregas (2005). La tesis del colonialismo genovés ha sido, por lo demás, convenientemente matizada por otros autores. Véase, por ejemplo, la revisión de López de Coca (1987, p. 289) de su anterior apoyo a la misma (López de Coca, 1973). 
Desde el poder se fomenta una actividad fiscalmente rentable y estratégicamente favorable a la hora de sumar apoyos e intereses implicados en momentos de crisis. El caso más emblemático lo protagonizan las citadas relaciones con Génova ${ }^{17}$. Aunque su importancia ha sido matizada conforme se han ido conociendo con mayor detalle las fases de su trayectoria y la naturaleza de las relaciones mantenidas con otras potencias, como la catalana ${ }^{18}$, lo cierto es que los genoveses siguen marcando el devenir de la notable presencia mercantil extranjera en el reino. La serie de tratados, estipulados y sucesivamente renovados durante los 180 años transcurridos entre el primero (1279) y el último (1479) conocidos, muestra, como constante que preside su espíritu de colaboración y entendimiento, el estímulo a las actividades comerciales en territorio nazarí y la protección y apoyo a quienes las llevan a cabo ${ }^{19}$.

La situación hasta aquí expuesta nos introduce en una realidad constituida por dos elementos caracterizadores básicos. De un lado, sobre todo a partir del siglo XIV y durante todo el $\mathrm{XV}$, nos encontramos ante un Estado plenamente implicado en la gran trama internacional de los negocios propia del panorama económico del Occidente europeo. De otro, toda participación granadina en este entramado comercial, bien como proveedora y consumidora de los artículos ya conocidos, bien como cabeza de puente entre el Occidente cristiano y el musulmán, es liderada por operadores ajenos a la sociedad nazarí, aunque, como veremos, no sin la intervención del cuerpo mercantil indígena. Todo ello se hace evidente mediante la observación de una serie de indicadores que pasamos a enunciar.

\subsection{Presencia de comunidades mercantiles extranjeras en suelo nazarí}

La presencia de comunidades mercantiles foráneas, entre ellas de las más destacadas en el panorama de los negocios internacionales, es un hecho. Son conocidísimas las comunidades mercantiles genovesa y catalana, de presencia constante y patente a través de referentes físicos, vínculos y estrategias de intervención directa. A éstas acompañan también otras presencias menos obvias, quizás no tan determinantes en la estrategia económica del Estado nazarí, aunque no por ello ajenas a la misma. Es el caso de las comunidades veneciana, florentina y portuguesa.

17 Empeñada en el establecimiento en la península Ibérica de un sistema de comercio que cuente con la "estrecha colaboración de los mercaderes autóctonos de la zona" (Iradiel, 1996, p. 162). Para los casos valenciano y sevillano, véase Igual (1992).

18 Los trabajos realizados por Gari (1989) o Salicrú (1998) se han centrado en aclarar y precisar la naturaleza de tales vínculos, y han puesto de relieve la relevancia de las relaciones mantenidas con otros grupos mercantiles, como los catalanes (Salicrú, 1999).

19 Véanse Lisciandrelli (1960); Gari (1985); Pistarino y Gari (1990), y Salicrú (1997) y (1998). 
Venecia permanecerá fiel más que cualquier otra potencia comercial a su vocación levantina, aunque conviene no olvidar que veneciano es, precisamente, uno de los sistemas de transporte, comunicaciones y negocios mejor formulados en el nuevo polo mediterráneo occidental y atlántico: el sistema de las mudas o convoyes organizados por iniciativa estatal, con rutas de tráfico definidas ${ }^{20}$. Algunas de ellas, las más relevantes de la región, tocan las costas granadinas: son la muda o Traffego de Berbería, que desde 1436, y partiendo del puerto valenciano, recorría las costas magrebíes con escalas en Trípoli, Djerba, Túnez, Bugía, Argel, Honein, Orán, Vélez de la Gomera, Málaga y Almería; y la muda de Flandes, muy anterior —al menos desde casi un siglo antes, según la documentación de Tenenti y Vivanti-, y que incluye entre sus escalas puertos nazaríes, con paradas previamente estipuladas $u$ ocasionales en Málaga ${ }^{21}$, Almuñécar y Velez-Málaga en los viajes de retorno ${ }^{22}$. Obviamente, ello supone el florecimiento mercantil del entorno veneciano en las tierras que toca su flota. De hecho, sabemos de la inclusión granadina en la red consular veneciana, al menos, desde $1400^{23}$, manteniendo ya en 1403 relaciones fluidas con otras comunidades mercantiles, que se sirven de ella ${ }^{24}$. Por el momento poco más se puede decir acerca de esta comunidad mercantil, cuya presencia y actividad en el reino podría depararnos aún muchas sorpresas.

La actitud y declaraciones de un toscano, Tuccio di Gennaio, han aportado pistas de gran interés para aclarar las estrategias de intervención de comunidades hasta ahora consideradas de menor relieve en el contexto nazarí. Este mercader, destinado en Málaga por la compañía florentina de los Alberti, al menos entre 1402 y 1406, confiesa que "He obtenido del rey el privilegio de que disfrutan los genoveses para descargar [mercancías] y guardarlas durante seis meses antes de volver a embarcarlas sin pagar derecho alguno, lo cual es una gran ventaja teniendo en cuenta los grandes derechos que se pagan aquí" 25 . La afirmación nos llevó en su momento a pensar, en primer término, que el volumen de operaciones efectuadas por mercaderes de nacionalidades ajenas a la genovesa era más elevado de lo supuesto a partir de los testimonios analizados hasta entonces. En segundo lugar, planteaba la posibilidad de que aquéllas se realizaran de manera encubierta bajo el auspicio de la comunidad genovesa, a la que cualquier mercader con intereses en Granada querría pertenecer a fin de disfrutar de sus prerrogativas ${ }^{26}$. No es una práctica nueva, ni para los mercaderes

Tenenti y Vivanti (1961).

Archivio di Stato di Prato (ASP, en adelante), Archivio Datini (AD, en adelante), Filza 1.072, Ibiza-Mallorca, 903164, 16/XII/1400.

ASP, AD, Filza 1.072, Ibiza-Mallorca, 801336, 23/II/1403.

López de Coca (1998), p. 402.

ASP, AD, Filza 999, Málaga-Valencia, 518349, 14/VI/1403.

ASP, AD, Filza 1.072, Málaga-Mallorca, 903195, 2/XI/1402.

Fábregas (2001). 
florentinos, que en otras plazas disponen de estatutos que manifiestan abiertamente la posibilidad de acogerse a esta solución ${ }^{27}$, ni para otros grupos mercantiles. Sánchez Martínez ya presentó el caso del mallorquín Jaume Manfré de ese modo ${ }^{28}$. Su vínculo con la compañía genovesa de los hermanos Pagani (Beneyto y Lavanyno de Pagé) se comprueba en 1320, aunque la denuncia de que es objeto en 1333 señala ya con total claridad su gran cercanía a la comunidad genovesa. Según algunos testigos, su asimilación a ésta llega a tal extremo que, durante su estancia en el reino nazarí, reside en la alhóndiga genovesa, en vez de en la catalana, y se comporta como súbdito genovés. El mismo Manfré reconoce en 1333 ser "franch en Espanya axí com genovés". Se trata de una prerrogativa que su socio, Nicolau Sallembe, admite ser común a otros mercaderes mallorquines que ejercían su actividad en Granada. Disponemos, pues, de varios indicios acerca de la verosimilitud de esta hipótesis: algunas comunidades de mercaderes extranjeros, cuyas naciones no podían dispensarles protección mediante un trato directo con el Estado nazarí, interesadas pese a todo en disfrutar de los beneficios que podía reportarles su actividad en suelo granadino, aprovecharon las condiciones propicias que les brindaba la organización, infraestructuras y redes de otras comunidades allí establecidas, fruto de la firma de tratados muy ventajosos.

\subsection{Grandes familias, grandes compañías}

Estas comunidades o naciones, representadas en algunos casos por las principales estirpes mercantiles europeas, conectan las bases nazaríes con los principales mercados peninsulares y europeos a través de una nutrida red de contactos. Es notoria, por ejemplo, la genovesa saga de los Spinola, que actúa como núcleo articulador en Málaga de una red de relaciones cruzadas que contribuye de manera decisiva a colocar la plaza nazarí en el contexto internacional. También es conocido su peso en las comunidades mercantiles de Flandes durante toda la Edad Media. Allí establecerán la base de una sociedad que organizará todos los movimientos de la familia a lo largo y ancho de Europa, especializándose, como la mayoría de mercaderes italianos en Brujas, en el sector textil y en la importación de alumbre ${ }^{29}$. En cuanto al control de las costas del extremo occidental mediterráneo, se establece a través de unas redes de contactos que combinan los vínculos familiares y societarios con las colaboraciones externas. El análisis del manual de la nave de Filippo di Nigro $^{30}$ nos permitió,

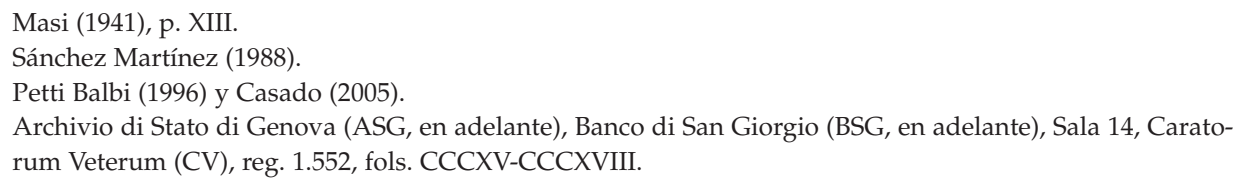


por ejemplo, reconstruir las redes de comunicación activas en 1445 con plazas magrebíes como Túnez, garantizadas por la presencia de miembros de su sociedad familiar, como Andrea y Vicinguerra Spinola. Recurren también a contactos menos directos. Así, Agostino Spinola, presente en Granada, cuenta en Hunayn con el hermano de su colaborador Jane Marchono, Raffaele Marchono, y en Cádiz con la sólida presencia de su cuñado, perteneciente a la familia Lomellini, activo en el área Cádiz-Sevilla. Este último, junto a colaboradores castellanos, como Francisco de Morales, parece ser el soporte en la zona de un mercader asentado en Sevilla, Jacobo Lomellino, muy activo en el área nazarí a través de sus contactos en dicha zona (Agostino y Filippo Spinola y Jane Marchono) y, por supuesto, ligado a los mercados septentrionales, a través de otros representantes de la familia Spinola destacados en Londres (Rabelle), Túnez (Costantino de Marinis) y la misma Quíos (Lodisio de Fornaris).

Un ejemplo quizá más emblemático, por la relevancia del personaje en cuestión, es el de otro miembro de la familia Spinola presente en Granada: Francesco Spinola q. Pietri. A través de su contabilidad conocemos que está emparentado con otra familia de gran renombre, los Fieschi, y con uno de los hombres de negocios más conocidos del momento, Giovanni Piccamiglio, su cuñado. Declara, además, sus buenas relaciones con las familias Fornario y de Nigro, al igual que con la familia Centurione, bien asentada en la península Ibérica gracias a su presencia en los principales centros de negocios, entre los que están Valencia, Sevilla y la misma Granada $^{31}$. En cuanto a sus colaboradores más directos, aparecen tanto en las grandes plazas europeas -Brujas (Luciano Spinola q. Carloti), Inglaterra (Pietro Spinola q. Georgi), Génova (Bartolomeo Sauli)—, como en el mismo reino granadino, con operadores e interlocutores con la población local en Málaga (Benedetto Cattaneo filio Anfreoni, Franco de Vivaldi) o Granada (Cristoforo Judex), y con otros que actúan indistintamente en Almuñécar, Almería y Málaga (Brancaleone Spinola o Pietro di Fornario).

De no menor peso es la sociedad familiar de los florentinos Alberti, para quienes trabaja en Málaga el ya citado Tuccio di Gennaio, autor del lote de correspondencia que certifica la presencia y actividad de una comunidad florentina en el reino. La compañía, regentada a principios del siglo XV por Diamante y Altobianco degli Alberti, está activa en plazas del Mediterráneo occidental y mantiene intereses en el Mar del Norte, haciendas en Brujas, Londres y París, vínculos con el Mediterráneo occidental y Portugal, y factores en Valencia, Barcelona, Málaga, Sevilla, Lisboa, Venecia, Roma, Palermo y Pisa ${ }^{32}$.

31 Boscolo (1977), p. 343, y López de Coca (1989).

32 Melis (1976). 
A través de este tipo de personajes, como Tuccio di Gennaio, pueden participar de los negocios del reino grupos que no tienen una presencia efectiva en el mismo, caso de la poderosa compañía de Francesco di Marco Datini. Éste y sus socios no consideran en ningún momento la necesidad de destinar allí un operador mercantil, aunque no por ello renuncian a oportunidades de negocios, para las cuales se sirven de la disposición de Gennaio y de otros mercaderes, como el cónsul veneciano Corner. En todo caso, el contacto parece constante; además, en ocasiones, operadores "datinianos" destacados en plazas como Sevilla, se desplazaron hasta Granada, como ocurre en 1404 con Antonio Covoni ${ }^{33}$. Ello explica que los registros de la compañía recojan entre los años 1383 y, al menos, 1408, hasta 24 señalaciones de cargamentos de naves que han tocado las costas nazaríes y que transportan artículos granadinos que interesan a la gente de Prato $^{34}$.

Es un tema que deberá abordarse con mayor detenimiento en otro momento, sobre todo en lo relativo a las redes de conexiones peninsulares. La importancia que adquieren estas redes de contactos, que establecen y utilizan los mercaderes a lo largo y ancho de la gran plataforma mercantil, se refleja de manera evidente en las más recientes tendencias de investigación en este campo. Se abandona definitivamente la idea de un mercader aislado y autosuficiente, para abordar el rico universo de interrelaciones, dependencias y colaboraciones que sitúan al hombre de negocios como parte de un sistema de organización cada vez más complejo y sofisticado ${ }^{35}$.

En nuestro caso estamos, desde luego, ante una red de relaciones y contactos muy compleja, en la que prevalecen los vínculos de colaboración e interdependencia. Sólo así el mercader, atento a la evolución del área a la que ha sido enviado o que ha seleccionado él mismo como centro de negocios, puede ejercer plenamente su actividad, completa sólo cuando se vuelve interactiva con otras áreas económicas. La trama de contactos se sirve de una serie de plazas que funcionan como bases de operaciones de este tipo de mercaderes allí destacados, que en muchas ocasiones se presentan a la vez como puertos, mercados y plataformas de penetración y control del territorio que lideran comercialmente. Recordemos que un puerto de estas características no es sólo un punto de atraque, ni un mero desembarcadero de mercancías, sino el observatorio desde el que se reconocen los territorios adscritos al polo de intercambios, en connivencia, generalmente, con los núcleos de control político, situados en el interior y desde los que, en sintonía con el poder político, otros mercaderes marcan las directrices estratégicas de la compañía o sociedad de la que forman parte.

33 ASP, AD, Filza 893, Málaga-Barcelona, 418030, 14/XII/1404.

34 ASP, AD, Filza 1.171/I, docs. 6, 7, 12, 17, 26, 34, 52, 53, 61, 67, 85, 89, 92, 106, 107, 109, 113, 134; Filza 1.171/II, fols. 3r-v., 4 r., 14 r., 16 v.-17 v., 21 v.

35 Molho y Ramada Curto (2003), Casado (en prensa b) y Murray (2005). 


\subsection{Articulación portuaria del reino nazarí}

El reino abre sus puertos al tráfico internacional, creando una trama de conexiones marítimas cada vez mejor conocida, a través de la creación de un sistema de puertos y entrepuertos con capacidad para sustentar una red de intercambio local, regional e internacional. En líneas generales, podemos decir que los puertos nazaríes desempeñan en el gran sistema de navegación y comercio que se organiza en torno a la ruta transoceánica un apoyo fundamental. Se trata de un sistema muy marcado por las tradicionales pautas de navegación mediterránea, en las que el cabotaje y el sistema de escalas de aprovisionamiento e intercambio tienen una notable trascendencia. Por otro lado, constituyen en sí mismas importantes sedes regionales, en la mayoría de los casos centros nodales de la circulación y vías de salida comercial de sus respectivos territorios circundantes. La eficacia de bases portuarias, como Málaga, en este sistema está presente en los más variados conjuntos documentales procedentes de las principales naciones mercantiles. A la rica documentación notarial genovesa cabe añadir la correspondencia de sociedades privadas toscanas como la de los Datini. Recordemos los ya citados cargamentos de naves (Carichi di navi) que en ocasiones se adjuntaban a las cartas. En los seguros marítimos genoveses se propone la estancia optativa en Cádiz o Málaga ${ }^{36}$; mientras que en la práctica totalidad de los viajes registrados en los Carati Maris a partir de 1436 se descubre una ruta que toca sucesivamente Cádiz y Málaga en estos trayectos atlánticos ${ }^{37}$.

Lo cierto es que, excluyendo por supuesto cualquier atisbo de rigidez en un sistema particularmente abierto y polivalente, cada vez más se identifica una suerte de especialización de ámbitos y comunidades de influencia en las actividades de los dos principales puertos nazaríes. Málaga, ámbito de actuación preferentemente genovés, tiene un papel más definido en las grandes rutas internacionales que recorren el Mediterráneo central y conectan éste con las plazas del Atlántico septentrional. Almería conserva una vocación regional y una actividad concentrada en el ámbito catalano-aragonés y sus derivaciones magrebíes. Por su parte, Almuñécar, que es reconocida como base portuaria en las rutas internacionales de navegación, desempeña un papel de relieve en la organización y apoyo al tráfico marítimo interno del mismo territorio nazarí, actuando como nexo de conexión entre las dos grandes escalas, Almería y Málaga, aunque con una subordinación directa al puerto malagueño y a intereses comerciales genoveses muy específicos, extensibles también a la localidad de Vélez-Málaga y relacionados con la famosa Ratio Fructe (Sociedad de la Fruta), de la que se hablará más adelante.

\footnotetext{
36 Doehaerd y Kerremans (1952), y Liagre (1969).

37 ASG, BSG, Sala 14, CV, reg. 1.552, fols. 35 r., 49 r.-50 r., 63 r.-64 v., 72 r.-v., 150 r.-151 r.
} 
El manual de la nave de Filippo de Nigro, redactado por él mismo durante el viaje que realiza con su barco en 1445, y conservado en el archivo de Génova, se presenta como modelo del sistema de navegación vigente en estos momentos. Involucra de manera directa a los puertos nazaríes al combinar la fórmula marítimo-mercantil del cabotaje, practicada en ámbitos territoriales más restringidos, con la gran navegación transoceánica ${ }^{38}$. El trayecto principal une el Atlántico norte (Southampton) con el extremo oriental del Mediterráneo (Quíos), si bien deja un margen muy amplio, por no decir central en el diseño del viaje, a la navegación de cabotaje realizada en el Mediterráneo occidental y central y a los movimientos comerciales espontáneos que de ella se derivan. De los seis meses empleados aproximadamente en completar el viaje, 18 días se invierten en atravesar el segmento atlántico en un recorrido sin paradas, aparte de las estrictamente técnicas. A partir de aquí se inicia la sucesión de escalas económicas que se abren con una estancia de 10 días en Cádiz, a partir del 23 de junio, y que han de finalizar el 22 de septiembre en Sicilia. Durante este lapso, sujeto a la decisión última del patrón de la nave, se efectúan negocios en los puertos de Málaga, Orán, Hunayn, Túnez y Bujía. Málaga se constituye, por tanto, en una suerte de "plataforma giratoria" del tráfico regional y en el soporte de las grandes líneas del sistema mercantil internacional.

A este sistema de comunicaciones debemos añadir una última ruta que conecta las costas andalusíes y magrebíes, y que comparten plenamente los puertos almeriense y malagueño ${ }^{39}$. Es importante señalar también que se trata de la única ruta conocida en la que está vigente el uso de medios de transporte cristianos y musulmanes. El sector oriental, liderado por el puerto almeriense, con bases auxiliares en Porto Genovese, Almuñécar e incluso Motril, presenta un radio de actuación más limitado, operando en Orán y Honeyn, además de en la Bãdis, ya mencionada por Idrîsî y ubicada frente a las costas de Málaga. Por su parte, las operaciones iniciadas desde puertos occidentales, básicamente desde Málaga (ya que Gibraltar parece punto de partida de viajes que se limitan a cruzar el Estrecho hasta Alcazarquivir, Tánger y Ceuta), aunque también desde Marbella y Algeciras, presentan un radio de acción mucho más amplio, que las extiende hasta Bujía, Salé y Azammour. Tocan también Gomara (Vélez de la Gomera), Ceuta, Tánger y Tagaça. De este modo, se aprovecha el rol del puerto malagueño como mercado de intercambio y distribución de las corrientes internacionales, actuando como nexo de unión entre éstas y el Occidente islámico. Se contempla no sólo el propio territorio nazarí, sino también los estados magrebíes, cuyos artículos aparecen en el mercado malagueño listos para su redistribución en Europa, y desde donde se les suministran artículos europeos, especialmente paños nórdicos. 


\subsection{Artículos de comercio y presencia en el mercado europeo}

Se comprueba la presencia de productos nazaríes en las grandes plazas europeas, en algunos casos no de manera simplemente testimonial, sino con capacidad incluso de bloquear el mercado merced a técnicas y estrategias utilizadas por los grandes grupos mercantiles que participan en el mismo. Es bien conocido el lote de artículos nazaríes más demandados y presentes en el mercado internacional, a saber, la famosa tríada de frutos secos (uva pasa, higos y almendras), el azúcar de caña en sus diversas calidades (panes de una, dos o tres cocciones y polvos de azúcar) y la seda en hilo. Nos referiremos a ellos con algo de más de detalle en breve.

Pero la exportación nazarí no se limita, ni mucho menos, a estos artículos. La cerámica de lujo, por ejemplo, es un bien que, aunque no deja grandes trazas de su circulación en las fuentes escritas, sí está documentado en los estudios arqueológicos; el seguimiento y la localización de sus restos materiales aportarán, probablemente, nuevas e interesantísimas informaciones acerca de rutas de comercio secundarias seguidas por artículos nazaríes en el mercado europeo. Hasta el momento se ha comprobado su presencia en puertos ingleses como Southampton, a finales del siglo XIII y en el siglo XIV, localidades costeras desde donde podría haber penetrado en mercados interiores como los de Londres, Penhallan (Cornualles) o Winchester ${ }^{40}$; también en los Países Bajos, concretamente en Middelburg (Holanda) ${ }^{41}$, y en Portugal ${ }^{42}$. El sur de Francia constituye otra área de recepción de cerámica nazarí, documentada en la Lleuda de Colliure ${ }^{43}$, y, en contextos de principios del siglo XIV, en Marsella, Aix-en-Provence, Hyères y Beaucaire ${ }^{44}$. Por último, la península italiana aparece como un área de recepción clásica de la cerámica nazarí ${ }^{45}$, con particular presencia de las variantes más lujosas de loza azul y dorada en las grandes plazas comerciales de Liguria (Génova y Savona), en centros secundarios de la región (Varazze, Finalborgo), en Toscana (Pisa, Florencia y Prato) y en Cerdeña (identificada mediante análisis petrográficos dentro del conocido como grupo Pula ${ }^{46}$. Por lo demás, una primera aproximación a las transmisiones tecnológicas que dan lugar a ciertos tipos de producciones cerámicas, apoyan el convencimiento de los autores de estos estudios de que se trata de una cerámica de naturaleza suntuaria, ideada, producida y adoptada desde el primer momento con la intención de satisfacer una demanda exterior ligada al comercio internacional ${ }^{47}$.

\footnotetext{
Hurst (1977), pp. 76-84.

Referencia indirecta localizada en Hurst (1977), p. 79.

Correia (2004).

Gual Camarena (1968), cap. XXIV, [138], p. 167.

Demians y Vallauri (1988), p. 88.

García Porras (2000), pp. 133-135.

Blake, Hughes, Mannoni y Porcella (1992).

García Porras (2003).
} 
Los artículos de mayor éxito comercial del reino son, en la mayoría de los casos, bienes asociados también al lujo, de tradición productiva oriental y que llegan a constituir el centro de proyectos de monopolio comercial por parte de grupos mercantiles sólidamente asentados, como la Sociedad Spinola, que alcanzaron resultados dispares. Su presencia en los mercados europeos es clara, y su distribución lógica y equilibrada. Así, la seda nazarí, exportada como materia prima, tiene como destino principal, aunque no único, los más importantes centros de producción textil sérica de Europa, que se sitúan fundamentalmente en ciudades italianas. De hecho, la actividad de grupos mercantiles toscanos está muy ligada a la adquisición de seda nazarí para su transporte a los talleres sederos, sobre todo a los de Florencia y Lucca. Por su parte, la incorporación catalano-aragonesa a la producción sérica en el siglo XIV, a partir de las iniciativas valencianas, podría justificar no sólo la continua llegada de barcos cargados de esta materia prima al puerto de la Grau, sino incluso los intentos de monopolización de las exportaciones sederas protagonizados por mercaderes valencianos en $1417^{48}$.

En cuanto a la otra gran partida de artículos nazaríes, los frutos secos y el azúcar, que constituyen un grupo de explotación homogéneo, su presencia es mucho más capilar. Se extiende desde los mercados atlánticos ingleses y flamencos hasta plazas levantinas como Constantinopla (Pera), pasando, por supuesto, por los centros del Mediterráneo central italianos (Génova, Savona, Pisa, Florencia), franceses (Aigües Mortes, constituye junto a Marsella, en menor medida, el acceso a los dos grandes centros meridionales, Montpellier y Aviñón, puertas de entrada a los mercados continentales) y catalanes (Barcelona, Valencia).

No obstante, las fuentes apuntan a una creciente presencia en los mercados del norte de Europa (Londres, Brujas y París, los vértices del gran triángulo septentrional, que aparecen como mercados de recepción de estos productos de manera prioritaria y continua), marcada, quizá, por los intereses de la sociedad que gestiona de manera mayoritaria su exportación: la conocida como Sociedad de la Fruta o Ratio Fructe, liderada por la genovesa familia de los Spinola. Ésta, que controla el mercado septentrional de los frutos secos, actúa en operaciones coordinadas que tienen como resultado la recepción masiva en dichos mercados, e incluso en el Algarbe portugués, de las mercancías granadinas ${ }^{49}$. Los Spinola disponen para ello de los medios y de las infraestructuras adecuadas ${ }^{50}$, cuentan con una flota propia y con la posibilidad de recurrir en todo momento al flete de embarcaciones ajenas dedicadas en exclusiva al transporte de sus bienes. Las mercancías son expedidas, básicamente,

\footnotetext{
$48 \quad$ Gari y Salicrú (1996), p. 209.

49 ASP, AD, Filza 980, Brujas-Valencia, 604951, 24/XII/1408.

50 Una descripción más detallada de todo el sistema de transporte, distribución y venta de frutos secos y azúcar desarrollado por esta sociedad, en Fábregas (2002b).
} 
desde Málaga y Almuñécar, aunque en ocasiones también desde Vélez-Málaga e, incluso, desde otros loca caricatoria regni Granate ${ }^{51}$ que no quedan especificados. Los mercados de recepción final se deciden aprovechando la extensa y tupida red de contactos que la familia mantiene, y que integra a los principales centros económicos europeos, tanto del polo septentrional como del Mediterráneo. Sus miembros poseen, en muchos casos, capacidad de maniobra y experiencia más que probada en la gestión de los negocios familiares en los mercados europeos. Se recurre también a colaboraciones temporales con otros integrantes de la familia de reconocida capacidad operativa y prestigio en otras áreas. El resultado es un desbordamiento del mercado, copado periódicamente por lo masivo de las cantidades introducidas, que vienen a monopolizarlo e incluso a bloquearlo. La estrategia la sufren con especial virulencia en algunos momentos otros grupos que pretenden introducirse en el mercado flamenco de los frutos secos, a través de su labor en otras áreas de aprovisionamiento de la misma península Ibérica (como los territorios de Alicante y Denia), y que han de estar particularmente atentos a los momentos de recepción de la mercancía en las bases septentrionales si quieren mantener un mínimo de competitividad.

\section{Actividad mercantil en el reino nazarí}

Todo lo anterior revela la progresiva implantación de las estructuras mercantiles y la penetración de las mismas en la estructura socioeconómica del reino, que corre pareja a su presencia en los principales mercados europeos. Trascendiendo este planteamiento general de la situación, carecemos aún de un discurso bien articulado en torno a cuestiones más complejas y específicas, relativas, sobre todo, a la gestión de estas actividades en el territorio nazarí y a las implicaciones que todo ello puede tener en la evolución de unas estructuras sociales y productivas sólidamente establecidas en el seno de las sociedades islámicas. En otras palabras, y presentando con ello las principales líneas de investigación emprendidas en los últimos años en torno a este tema, no sabemos cómo actúan estos grandes grupos mercantiles en el reino y no llegamos a comprender aún en qué medida su actuación rompe las estructuras de base de una organización productiva cimentada en la agricultura, muy rica, ciertamente, pero en la que las imposiciones sociales exigen la subsistencia como salida económica de comunidades independientes y que gestionan sus propios recursos de manera autónoma ${ }^{52}$.

51 Así son citados en repetidas ocasiones en la documentación notarial genovesa.

52 Antonio Malpica Cuello ha trazado últimamente un acertado enfoque de la cuestión, planteado a partir del análisis de los presupuestos sociales de una formación de matriz islámica, como la nazarí, y de la propuesta de los grandes temas que deberían ser tratados al respecto (Malpica, 2004). 
Nuestra tarea, aún por concluir, se ha centrado en el primer punto, sobre el que podemos ya proponer algunos apuntes. La comunidad genovesa, de presencia más sólida y de mayor riqueza testimonial, ha centrado nuestros esfuerzos, y a ella nos referiremos en adelante casi en exclusiva. Elegimos como guía al ya conocido Francesco Spinola q. Pietri y a sus registros contables de los negocios que desarrolla en el reino de Granada entre los años $1434-1440$ y $1451-1455^{53}$. Se trata de un personaje relevante en el mundo de los negocios nazaríes, líder de la comunidad mercantil genovesa en el reino, bien relacionado con los sectores de poder nazaríes y con una presencia notable en el panorama comercial internacional. Su actividad mercantil está permanentemente vinculada a este reino, aun cuando su sede de operaciones sea otra y su ámbito de actuación y el de la familia, en cuyo seno trabaja, mucho más amplio que el estrictamente granadino ${ }^{54}$. A título indicativo acerca de su volumen de negocios en el reino, podemos aportar las cifras que destina a operaciones mercantiles de compraventa vinculadas al mercado nazarí en el período comprendido entre 1451 y 1457, fecha de su última estancia en Granada, y que aparece en su contabilidad. Se trata de una época en la que percibimos una cierta atenuación de su actividad mercantil, que se muestra mucho más selectiva a la hora de participar en cierto tipo de operaciones, sobre todo respecto a etapas anteriores que podríamos considerar como los momentos álgidos de su actividad. Aun así, Francesco Spinola participará en operaciones ligadas a la compraventa de paños, para los que destina un total de 8.593 libras genovesas, seda (7.913 libras), frutos secos (958 libras), cueros (23 libras), florines de oro (377 libras), oro hilado (327 libras), nuez de agalla (81 libras), almendras (280 libras) y dátiles (362 libras), además, por supuesto, de su participación permanente como miembro activo de la famosa Sociedad de la Fruta y de sus actividades financieras que lo ocupan por entonces de manera más directa ${ }^{55}$.

\subsection{Naturaleza de la intervención}

En primer lugar, hemos de decir que los comerciantes descritos no participan directamente en la actividad productiva del reino, aunque evidentemente sí pueden condicionarla mediante la demanda de ciertos artículos. Nos basamos para realizar esta

53 Localizados en el Archivo Durazzo-Giustiniani (AD-G, en adelante), sección Sauli (S), siglas 1.839 y 1.842, respectivamente. Forman parte de un conjunto más amplio al que se añaden otros dos redactados por Francesco Spinola q. Petri en Brujas (1420-1426) y Génova (1446), y uno más de otro miembro de la familia residente también durante un tiempo en el reino granadino, Agostino Spinola q. Johanis. La serie granadina, constituida por este último ejemplar y por otros dos redactados por Francesco, son objeto de un proyecto de estudio y edición, habiéndose publicado ya dos de ellos en Fábregas (2002a) y (2004). La labor continuará con la edición, ya en preparación, del tercer y último registro redactado en tierras granadinas entre los años 1434-1440.

$54 \quad$ Petti Balbi (1997).

55 Fábregas (2004). 
afirmación en el hecho de que las informaciones disponibles hasta el momento conciernen única y exclusivamente a tácticas de aprovisionamiento desarrolladas por estos grupos mercantiles, y en ningún caso a detalles relacionados con la producción de los bienes objeto de comercio, como puede ocurrir ya en estos mismos momentos en otras zonas $\left(\right.$ Chipre $^{56}$, Portugal $^{57}$, Sicilia ${ }^{58}$ o Valencia ${ }^{59}$ ). Este extremo se comprueba en el caso de los artículos más emblemáticos de la exportación nazarí, a saber los frutos secos y la seda. En el primer caso, la sociedad que gestiona este negocio, la ya conocida Ratio Fructe, parece precisamente tener la prerrogativa de su aprovisionamiento, que no de su transporte y venta exclusiva en los mercados europeos ${ }^{60}$, y desde luego no respecto a su producción, en la que se detecta la participación genovesa sólo en momentos posteriores a la conquista castellana.

En cuanto a la seda, ya hemos dicho que es una materia prima muy demandada por los principales centros textiles europeos. De nuevo nos encontramos con variadas fórmulas de aprovisionamiento, que en algunos casos denotan la inadecuación de la oferta a la demanda y, por tanto, la animada competencia que surge a la hora de adquirir los mayores volúmenes de producción posibles. Así, por ejemplo, los mercaderes toscanos tienden a acudir a un centro de redistribución externo al reino granadino, como Valencia, para hacer acopio de esta materia prima. Por su parte, la conocida fórmula de permuta que los genoveses aplican de manera reiterada al negocio sedero, puede contener no sólo un intento de reducir los costes de la transacción: el intercambio de paños de diversa procedencia, principalmente inglesa y valenciana, por seda en Granada se lleva a cabo en las alcaicerías, hacia donde se deriva por motivos de control fiscal. Queda claro en el caso de nuestro mercader Spinola su recurso mayoritario a la alcaicería granadina, aunque no deja de realizar compras en los otros grandes centros de Málaga y Almería. Y aún más, mantiene contactos y gestiones con mercaderes locales procedentes de otras zonas productoras de gran relieve, como la Alpujarra y Almuñécar, donde la transacción tiene lugar

56 A mediados del siglo XIV, la familia veneciana de los Cornaro, dedicada al comercio hasta entonces, adquiere en Piskopia gran cantidad de tierra, que dedica al cultivo de caña dulce (Greenfield, 1991, y Verlinden, 1968, p. 40).

57 En 1404, el rey João I concede al mercader genovés Miçer Joan de Palma terrenos en Quarteira (Algarbe) para la plantación de caña, a lo que se añaden algo más tarde nuevas concesiones a la misma familia, esta vez en Loulé. Arquivo Nacional Torre do Tombo, Chancillería, D. João, liv. II, fol. 200; y liv. III, fol. 111 r.

58 El negocio azucarero siciliano será impulsado definitivamente a partir del siglo XV gracias al apoyo del gran capital mercantil y financiero (Bresc, 1986, p. 248).

59 El primer trapiche que tenemos documentado data de 1418 y surge a partir de la iniciativa conjunta del rey, el cambiador Francesch Siurana, el mercader Johan Bayona y el maestro azucarero Nicolau de Santafé. Archivo de la Corona de Aragón, Cancillería 2.412, fol. 120 v.

60 Sabemos de la adquisición de azúcar granadina en los mismos puertos nazaríes por parte de mercaderes de otras nacionalidades, venecianos, florentinos, catalanes e, incluso, genoveses, ajenos a esta sociedad de explotación (Fábregas, 2002b, p. 34). 
en una alhóndiga. A través de operaciones de este tipo se obtiene la no desdeñable posibilidad de entrar en contacto con los proveedores de seda, mercaderes locales que resultan ser pequeños y medianos comerciantes de paños que actúan en la red local de mercados regionales que cubre el territorio nazarí, y que, en última instancia, serán los interlocutores directos entre el mercader extranjero y el productor de seda granadino.

En todo caso, se trata siempre de fórmulas de aprovisionamiento, no de producción o de participación en la misma. Incluso cuando conocemos intentos de monopolización por parte de algún colectivo, como el famoso monopolio de la seda obtenido por mercaderes catalano-aragoneses en 1417, éste se refiere única y exclusivamente a su exportación ${ }^{61}$. Así pues, cabe avanzar que los caracteres de la intervención de la comunidad mercantil genovesa afectan mucho más al control monopolístico de los mecanismos de acceso de tales artículos al mercado europeo, ya mencionado, que a la posible transformación de las estructuras productivas granadinas mediante su participación en las mismas. Evidentemente, la simple demanda ejercida por un mercado mucho más extenso resulta ser un estímulo fundamental para unos productores liderados por el propio Estado nazarí. Y en este sentido, la posibilidad de condicionamiento y reorientación en su propio beneficio de la actividad productiva de parte del territorio, aunque ésta sea reducida, supone una importante novedad.

\subsection{Las fórmulas y los actores de la intervención}

Esta afirmación conduce inevitablemente a la siguiente cuestión, que es la de elucidar quiénes son los interlocutores y colaboradores en territorio nazarí de estos grupos mercantiles que les permiten asegurarse el aprovisionamiento. Su implicación en la vida local se realiza a varios niveles, que abarcan todo el espectro social y económico del reino. Así, los encontramos vinculados directamente a los círculos de poder, llegando, como veremos más adelante, a tratar incluso con la corona y su entorno más inmediato. Estos contactos se realizan a través de sociedades de gestión del peso de la ya citada Ratio Fructe, o a nivel individual, sea en relaciones directas entre los más altos representantes de estos grupos, caso de nuestro Francesco Spinola o de sus colaboradores más directos, como Francesco Vivaldi, socio de Spinola y contacto del mismo con personajes de la talla del mismo rey, el alcaide de Málaga o los alfaquíes ${ }^{62}$.

61 Gari y Salicrú (1996), p. 209.

62 AD-G, S, ms. 1.839, fols. CXXXVIIII, CLXXI, CLXXVII, CLXXXXV. 
La Sociedad de la Fruta cuenta con operadores encargados de organizar las gestiones de compra, almacenamiento y distribución de la fruta y del azúcar, localizados en áreas productivas y de expedición como Vélez-Málaga, Almuñécar, donde se conoce incluso una domus Muleche de la sociedad (dedicada a recoger los azúcares producidos en el entorno inmediato de las vegas de los ríos Verde y Guadafeo), y la misma Málaga. Más revelador que este dato es, quizá, aquel otro que sugiere la existencia de una figura definida, el conocido como colector fructis, que actúa como interlocutor entre los mercaderes y la población local responsable de la producción. Este personaje, cuando ha podido ser identificado, resulta ser un exponente de relieve de la sociedad indígena.

La contabilidad de Francesco Spinola q. Pietri, miembro de esta Ratio Fructe, incluye la gestión de los titulares de dicho cargo entre 1436 y $1438^{63}$. Se trata de Alí Xaorolí, su sucesor, Cacim Sibilí, receptores de almendras, y Aborcacim Cortobí, los cuales desarrollan su actividad en el territorio de Málaga y Vélez-Málaga. La colaboración entre ambas partes se establece en un marco de confianza y conocimiento mutuo que propicia la perpetuación del cargo dentro de sagas familiares. Así, por ejemplo, Cacim Sibilí y su hermano Macomet son receptores de almendra y fruta, el primero en Málaga y el segundo en Vélez-Málaga, si bien las tareas están lideradas por Cacim, a cuyo nombre se abren todas las cuentas que recogen las operaciones de esta naturaleza realizadas indistintamente en uno y otro centro. Los lotes pueden ser adquiridos mediante compra por adelantado, bajo forma de dinero al contado o de permuta por otras mercancías, como paños o partidas de queso.

No conocemos ningún intermediario reconocido como tal, o incluido en este grupo de colaboradores, que actúe como receptor de azúcares. Sin embargo, las pautas de actuación respecto a este artículo parecen ser las mismas que se identifican para los frutos secos. De hecho, aunque no viene designado como tal, conocemos al mercader o, mejor dicho, a la sociedad mercantil que ejerce tales funciones en la costa granadina en 1436. Se trata de los judíos Aym Aben Xiec y su socio Maimon Coín, que organizan la recepción de azúcares y su entrega a la Ratio Fructe ${ }^{64}$. En este caso también se observa la constancia o fidelidad, que funciona tanto en los contactos institucionalizados con la Sociedad como en otro tipo de colaboraciones. La cooperación con la sociedad mercantil se retrotrae al menos hasta 1430, fecha en que se recogen varios testimonios que nos permiten confirmar la práctica de la permuta también en este negocio de aprovisionamiento del azúcar. En concreto, se trata del intercambio de 136 arrobas de azúcar de pote por cuatro piezas de paños largos de Londres ${ }^{65}$.

\footnotetext{
63 AD-G, S, ms. 1.839 , fols. 89 v., 128 v., 161 v., 168 v.

64 AD-G, S, ms. 1.839, fol. 13.

65 ASG, Notai Antichi, Branca Bagnara, 510, fols. 283 r. y 286 r. La operación la protagoniza un miembro de la familia Spinola, Vinciguera, en Málaga, con nuestro judío Aym A. Xiec, en Almuñécar.
} 
La contabilidad de Francesco Spinola q. Pietri muestra una red de socios y colaboradores, pertenecientes a la misma sociedad familiar o extraños a la misma, que lo sitúan entre la élite de los negocios granadinos y europeos. En primer lugar, cabe destacar su relación directa con interlocutores indígenas. Es el caso de un tal Said Soraichi, dedicado exclusivamente al negocio sedero en la alcaicería de Granada, y que pone en contacto a Spinola con otros proveedores de sedas, como Macomet Aben Carabos, Macomet Mero, Aborcacim Elbognoli, Macomet Aben Alag y Macomet Aben Mondir. O la sociedad constituida por los judíos Maimon Coin y Aym Aben Xiec, mercaderes de paños al por mayor de Almuñécar, tal y como muestra la contabilidad de Agostino Spinola q. Johanis, que ejercen de intermediarios financieros entre otros colegas locales y los genoveses, y protagonizan operaciones de intercambio de paños por azúcar o por seda. Ello se combina con valiosos y versátiles agentes, como Franco de Vivaldi, que se encargan de controlar y asegurar los contactos con miembros tan relevantes como los antes citados, y de hacerlo también con los sectores mercantiles y corredores de negocios nazaríes, presentes en las múltiples operaciones de adquisición de sedas que él mismo gestiona en las alcaicerías del reino.

Por su parte, miembros más humildes de la familia, como Agostino Spinola q. Johanis o Brancaleone Spinola, se ocupan de mantener los contactos entre el vértice de la comunidad genovesa, representado en este caso por Francesco, y la base mercantil local. El caso del primero, ya estudiado con algo más de detalle, nos permite identificar a uno de los protagonistas del estadio último de imbricación en la base productiva y mercantil del reino ${ }^{66}$. A través de una gestión técnicamente autónoma, ejecuta una imprescindible labor de intermediario entre los altos estamentos de la sociedad familiar a la que pertenece, y los segmentos medios y bajos de la población local. La contabilidad de un personaje como éste, ciertamente humilde dentro del gran sistema societario, presenta, sin embargo, una rica red de relaciones con el substrato mercantil indígena. Concretamente, aparecen en la misma hasta 75 hombres de negocios nazaríes, tanto judíos como musulmanes. Respecto a los primeros, podemos decir que representan una minoría como grupo de individuos, no así como factor financiero. En cuanto a los segundos, suelen protagonizar movimientos de menor entidad. Se identifican como pequeños comerciantes o artesanos.

\subsection{Los instrumentos utilizados}

La penetración en la estructura comercial nazarí efectuada a través de los interlocutores descritos, se lleva a cabo mediante las fórmulas e instrumentos comerciales a su disposición en estos momentos, y que resultan estar a la vanguardia del panorama 
internacional de los negocios. Por supuesto, no se limitan a una actividad desarrollada en el marco de la sociedad familiar, aunque hemos de decir que sí aparece en todo momento en estricta sintonía con los intereses de la misma. La gestión concreta de cada negocio parece recurrir a fórmulas de inversión como la comenda ${ }^{67}$. Ésta puede aparecer también bajo una fórmula más desarrollada y tendente, por lo general, hacia una mayor estabilidad, con la participación de un socio capitalista, aportando el resto su capacidad operativa a través de sus contactos y extrema movilidad ${ }^{68}$.

En cuanto a las fórmulas de intercambio, se recurre a un amplio espectro de ellas, como los pagos en efectivo y las operaciones a crédito, así como a la combinación entre pagos al contado y créditos a término. Por último, aparecen operaciones de permuta (baratta). La permuta resulta una práctica muy utilizada y de gran interés, por cuanto parece ser una fórmula muy adecuada para garantizar el aprovisionamiento de artículos tan valorados como la seda y el azúcar. En este sentido, el abastecimiento de paños al por mayor o en lotes más reducidos, que ocupa gran parte de la actividad y de las transacciones realizadas por nuestros mercaderes, ve multiplicar su margen discreto de ganancia al convertirse en la excusa u ocasión de obtener beneficios mucho más importantes. No olvidemos que una gran parte de los mercaderes locales con quienes se mantienen contactos aparecen como negociantes de paños, en cuya compra se muestran muy activos e interesados. Sin embargo, no participan en esta producción y en muchos casos no tendrían ni contactos directos con los productores, a no ser que éstos fueran identificados dentro de uno de los grupos arriba citados con los que mantienen relaciones. Esto nos lleva hasta el último punto que tenemos intención de esbozar en este trabajo.

\subsection{Una condición imprescindible: el mercader y el Estado nazarí}

Ya hemos aludido a que la relación con el poder de algunos de estos comerciantes es evidente, no sólo como beneficiarios de un trato de favor, sino como colaboradores, interlocutores e, incluso, agentes comerciales. A través de ellos identificamos en los círculos de poder a los únicos elementos nazaríes activos en el comercio exterior.

Francesco Spinola es, durante su estancia en Granada, uno de los miembros más relevantes de los intereses y actividades de la comunidad genovesa en la zona. Su

67 Comprobada en su fórmula más clásica en operaciones específicas llevadas a cabo con Agostino Spinola o en otros negocios, como la compra de lotes de pieles o de paños. A modo de ejemplo citamos algunos casos. AD-G, S, ms. 1.842, XXXVI v., XXXX v., XXXXI v., XXXXIII v., XXXXVII v.

68 En concreto, Francesco Spinola ofrece varios ejemplos de este tipo de sociedad comanditaria activa en Granada, con socios como Bartolomeo y Bandinelo Sauli, Nicolò de Fornario y Franco de Vivaldi, en una de ellas; o Luca Centurione, Enrico Pinelo y Pietro Spinola q. Zacaria en otra, establecida en el mismo reino en 1451. 
presencia a la cabeza del listado de damnificados en las querellas de $1452^{69}$ es indicio de ello. Sabemos, además, que, en sus años de mayor esplendor, está en contacto directo con la corona nazarí, a la que proporciona servicios financieros y mercantiles. Concede créditos al rey, convirtiéndose en el primer mercader genovés asiduo a una práctica detectada en otros estados y en momentos algo posteriores, y sabemos de su tarea como intermediario mercantil del rey granadino, en cuyo nombre efectúa cargamentos con objetos y destinos diversos. Gracias a su mediación, la corona nazarí tiene la posibilidad de acceder directamente a la plataforma mercantil europea.

Sabemos, pues, que resultan ser los únicos actores comerciales. ¿Tienen éstos peso productivo? En el caso de la corona parece ser que sí, aunque queda por elucidar el caso de otros mercaderes que podrían participar en áreas muy restringidas y particularmente penetradas por el comercio. Las propiedades que compra en 1492 Francisco de Madrid ${ }^{70}$ muestran a los antiguos dueños de algunas aduanas de azúcar localizadas en Motril. Una de ellas, la mayor, que era propiedad del alfaquí Basti, contaba, además, con un fadín de tres marjales de caña y con una enorme extensión de seiscientos marjales cuya dedicación no se especifica. Una segunda pertenecía a la reina Horra, propietaria también de los derechos de explotación de las salinas de Motril, que mantenía en régimen de monopolio, con un control que llegaba incluso a la comercialización de la sal, efectuada, al parecer, en tiendas de su propiedad.

Trabajos recientes de otros autores ${ }^{71}$ coinciden en subrayar la necesidad de abordar este punto de manera mucho más detenida. En este sentido se apunta la necesidad de tener en cuenta las posibilidades de aprovechamiento comercial de territorios como el secano e, incluso, de áreas de regadío, como algunas zonas de la vega granadina, de la vega de Salobreña, o de la misma ciudad de Granada ${ }^{72}$, posiblemente consideradas como parte del patrimonio real nazarí a través de mecanismos legales de apropiación de tierras, como la vivificación, sin que ello supusiera una interferencia decisiva y perjudicial en la dinámica productiva interna.

\section{Conclusiones}

Las nuevas tendencias historiográficas, que relativizan, o directamente corrigen, la distribución del sistema de comercio occidental a partir de relaciones de subordinación centro-periferia, incluyen el acercamiento a la historia comercial del reino

\footnotetext{
Airaldi (1966).

Archivo Histórico Nacional, Diversos (Títulos y Familias), leg. 1.794.

Malpica (2002) y López de Coca (2001).

Malpica (en prensa).
} 
nazarí de Granada. La incorporación de este pequeño territorio a la gran plataforma mercantil europea, que se viene constituyendo en estos siglos finales de la Edad Media, es plena y efectiva prácticamente desde el momento mismo de su conformación como Estado. Se enmarca, tal y como ocurre en otros casos ya bien identificados y estudiados, en un proceso de aceleración económica que, en estos momentos iniciales, utiliza como vía de crecimiento la actividad mercantil. Esta dinámica de desarrollo afecta en principio a todo Occidente. Se trata de un proceso de ritmos dispares, poco coordinado en su desarrollo, que involucra sucesivamente y a ritmos diferentes, pero de manera generalizada e, incluso, "envolvente" ya en estos momentos tan avanzados, a las grandes plataformas mediterránea y atlántica. Además, se registra no sólo en los espacios incluidos en la órbita cristiano-feudal, sino también en las áreas de filiación islámica.

De este modo, el desarrollo de sus estructuras y su faceta comercial no pueden ser interpretados fuera del contexto de crecimiento generalizado de la Europa bajomedieval, que sin duda alguna asume la integración económica de este territorio. Sin embargo, el tradicional rol de subordinación que se le atribuye como "colonia" comercial, ni corresponde probablemente a la realidad, ni constituye una explicación acertada de su propia evolución. La posibilidad de identificar una suerte de especialización agraria, orientada exclusivamente a la generación especulativa de bienes de comercio, se ha demostrado, hace tiempo, como ajena a la realidad socioeconómica nazarí, por muy desvirtuados que aparezcan ya sus principios sociales y productivos de base que encajarían en parámetros adscritos a la sociedad islámica.

También es cierto que todavía no podemos precisar el papel que juega en todo ello un territorio como éste, vinculado aún, como decimos, a un modelo económico calificado como "tributario-mercantil", ajeno, por tanto, a los principios generadores del impulso económico de Occidente. Sabemos que el cuerpo mercantil indígena, que participa en el desarrollo comercial en territorio nazarí, no lidera en ningún momento este impulso y que se mantiene como apoyo, inevitable, eso sí, de los mecanismos de penetración y conexión del mercado exterior con los ámbitos productivos nazaríes. Pero en estos momentos y bajo esta formación política no se llega a construir un cuerpo mercantil activo en la redes del comercio internacional.

La dinámica de mercado ha calado profundamente en las estructuras sociales y productivas nazaríes, y sin duda constituye uno de los más potentes agentes de disolución de su antigua conformación. Pero, a su vez, la tradición islámica del territorio la lleva a asumir caracteres particulares. Quizá sea el momento de abordar desde esta clave el estudio de ésta y otras áreas islámicas occidentales. 


\section{Bibliografía}

ABULAFIA, David (2002): "Italia e lo spostamento economico del XV secolo", en AURELL, Jaume, (ed.) El Mediterráneo medieval y renacentista, espacio de mercados y culturas, Pamplona, EUNSA, pp. 179-212.

AIRALDI, Gabriella (1966): Genova e Spagna nel secolo XV. Il liber damnificatorum in regno Granate (1452), Genova, Università di Genova.

ALARCÓN y SANTÓN, Maximiliano, y GARCÍA DE LINARES, Ramón (1940): Los documentos árabes diplomáticos del Archivo de la Corona de Aragón, Madrid, Estanislao Mestre.

BLAKE, Hugo; HUGHES, Michael; MANNONI, Tiziano, y PORCELLA, Francesca (1992): "The earliest Valencian lusterware? The provenance of the pottery from Pula in Sardinia", en GAIMSTER, David (ed.) Everyday and exotic pottery from Europe c. 650-1900. Studies in honour of John G. Hurst, Oxford, Oxbow Books, pp. 202-224.

BOSCOLO, Alberto (1977): "Gli insediamenti genovesi nel sud della Spagna all'epoca di Cristoforo Colombo", en Atti del II Convegno Internazionale di Studi Colombiani. Genova 6 e 7 ottobre 1975, Genova, Civico Istituto Colombiano, pp. 321-345. BRENNER, Robert (1988): "Estructura agraria de clases y desarrollo económico en la Europa preindustrial", en ASTON, Trevor H., y PHILPIN, C. H. E. (eds.), El debate Brenner. Estructura de clases agraria y desarrollo económico en la Europa preindustrial, Barcelona, Crítica, pp. 21-81.

BRESC, Henri (1986): Un monde méditerranéen. Économie et société en Sicile, 1300-1450, Roma, École Française de Rome.

CASADO ALONSO, Hilario (2005): "El papel de las colonias mercantiles castellanas de los Países Bajos en el eje comercial Flandes-Portugal e islas atlánticas (siglos XV y XVI)", en GARCÍA GARCÍA, Bernardo, y GRILO, Fernando (coords.), Ao modo da Frandes. Disponibilidade, inovação e mercado de arte na época dos descobrimentos (1415-1580). Actas do Congreso Internacional celebrado em a Reitoria da Universidade de Lisboa (Abril de 2005), Madrid, Fundación Carlos de Amberes, pp. 17-35.

-(en prensa a): "El comercio internacional castellano en tiempos de Isabel la Católica", en Actas del Congreso Internacional Isabel la Católica. Castilla, la monarquía hispánica, el mundo en tiempos de Isabel, Barcelona, noviembre de 2004.

-(en prensa b): "Las redes comerciales castellanas en Europa (siglos XV y XVI)", en Actas del Congreso Comercio y hombres de negocios en Castilla y Europa en tiempos de Isabel la Católica, Burgos, octubre de 2004.

CHIAPA MAURI, Maria Luisa (1973): "Il commercio occidentale di Genova nel XIV secolo", Nuova Rivista Storica, LVII, fasc. V-VI, pp. 571-611.

CORREIA, Miguel (2004): “Três exemplares de cerâmica azul e dourada, provenientes de Alcochete", Revista Portuguesa de Arqueologia, 7, pp. 645-652. 
DÉMIANS D'ARCHIMBAUD, Gabrielle, y VALLAURI, Lucy (1988): “Productions et importations céramiques médiévales dans le Midi méditerranéen français", en PADILLA LAPUENTE, José, y VILA CARABASA, Josep M. (eds.), Ceràmica medieval i postmedieval. Circuits productius $i$ seqüencies culturals, Barcelona, Universitat Autònoma de Barcelona, pp. 73-110.

DOERHAERD, René, y KERREMANS, Ch. (1952): Les relations commerciales entre Gênes, La Belgique et l'Outremont d'après les Archives Notariales Génoises, 1400-1440, Bruselas-Roma, Institut Historique Belge de Rome.

EANES DE ZURARA, Gomes (1988): Crónica do Conde Dom Pedro de Menezes, introducción de FREITAS CARVALHO, José Adriano, Porto, edición facsímil.

EPSTEIN, Stephan R. (2000): Freedom and Growth. The rise of states and markets in Europe, 1300-1750, Londres, Routledge.

FÁBREGAS, Adela (2001): "Estrategias de actuación de los mercaderes toscanos y genoveses en el reino nazarí de Granada a través de la correspondencia Datini", Serta Antiqua et Medievalia, V, Génova, pp. 259-304.

-(2002a): Un mercader genovés en el reino de Granada. El libro de cuentas de Agostino Spinola (1441-1447), Granada, THARG.

-(2002b): "Vías de acceso del azúcar del reino de Granada al mercado europeo: La Sociedad de los Frutos (Siglos XIV-XV)", en Actas do II Seminário Internacional sobre a História de Açúcar. Historia do açucar. Rotas e mercados, Madeira, pp. 23-53.

-(2004): La familia Spinola en el reino nazarí de Granada. Contabilidad privada de Francesco Spinola (1451-1457), Granada, THARG.

GARCÍA PORRAS, Alberto (2000): “La cerámica española importada en Italia durante el siglo XIV. El efecto de la demanda sobre una producción cerámica en los inicios de su despegue comercial", Archeologia Medievale, XXVII, pp. 131-144.

-(2003): "Los orígenes de la cerámica nazarí decorada en azul y dorado", en Atti XXXV Convegno Internazionale della Ceramica. Albisola, 2002, Savona, Centro Ligure per lo Studio della Cerámica, pp. 53-62.

GARI, Blanca (1985): "Génova y Granada en el siglo XIII: los acuerdos de 1279 y 1298", Saggi e documenti, VI, pp. 175-206.

-(1989): "La advertencia del fin. Génova y el reino de Granada a mediados del siglo XV", en Presencia italiana en Andalucía. Siglos XIV-XVII. Actas del III Coloquio Hispano-Italiano, Sevilla, Escuela de Estudios Hispano-Americanos de Sevilla, pp. 179-189.

GARI, Blanca, y SALICRÚ, Roser (1996): "Las ciudades del triángulo: Granada, Málaga, Almería, y el comercio mediterráneo de la Edad Media", en ABULAFIA, David, y GARI, Blanca, (eds.), En las costas del Mediterráneo occidental. Las ciudades de la Península Ibérica y del reino de Mallorca y el comercio mediterráneo en la Edad Media, Barcelona, Omega, pp. 171-211.

GREENFIELD, Sydney M. (1991): “Cyprus and the beginnings of modern sugar cane 
plantations and plantation slavery", en Actas del II Segundo Seminario Internacional sobre la Caña de Azúcar. La caña de azúcar en el Mediterráneo, Motril, Diputación de Granada, pp. 23-42.

GUAL CAMARENA, Miguel (1968): Vocabulario del comercio medieval, Barcelona, Diputación de Tarragona.

HEERS, Jacques (1961): Gênes au XVe siècle. Activité économique et problèmes sociaux, París, S.E.V.P.E.N.

HILTON, Rodney (1988): Conflicto de clases y crisis del feudalismo, Barcelona, Crítica.

HURST, John (1977): "Spanish pottery imported into medieval Britain", Archeologia Medievale, 21, pp. 68-105.

IGUAL LUIS, David (1992): “Valencia y Sevilla en el sistema económico genovés de finales del siglo XV", Revista d'Història Medieval. Valencia i la Mediterrània medieval, 3, pp. 79-116.

IRADIEL, Paulino (1986): “En el Mediterráneo occidental peninsular: dominantes y periferias dominadas en la Baja Edad Media", en PÉREZ PICAZO, María Teresa; LEMEUNIER, Guy; y SEGURA, Pedro, (eds.), Desigualdad y Dependencia. La periferización del Mediterráneo Occidental (s. XII-XIX). Áreas. Revista de Ciencias Sociales, Murcia, Editora Regional de Murcia, pp. 64-77.

-(1996): "Valencia y la expansión mediterránea de la Corona de Aragón", en ABULAFIA, David, y GARI, Blanca, (eds.), En las costas del Mediterráneo occidental. Las ciudades de la Península Ibérica y del reino de Mallorca y el comercio mediterráneo en la Edad Media, Barcelona, Omega, pp. 155-169.

LIAGRE DE-STURLER, Léone (1969): Les relations commerciales entre Gênes, la Belgique et l'Outremont, Bruselas-Roma, Institut Historique Belge de Rome.

LISCIANDRELLI, Pasquale (1960): Trattati e negoziazioni politiche delle repubbliche di Genova (958-1797), Genova, Società Ligure di Storia Patria.

LÓPEZ DE COCA, José Enrique (1973): “Málaga, 'colonia' genovesa (siglos XIVXV)", Cuadernos de Estudios Medievales, I, pp. 135-144.

-(1987): "El período nazarí (siglos XIII-XV)", en Historia de Granada. II: la época medieval, Granada, Don Quijote, pp. 243-368.

-(1989): “Mercaderes genoveses en Málaga (1487-1516). Los hermanos Centurión e Ytalian", en LÓPEZ DE COCA, José Enrique, (ed.), El Reino de Granada en la época de los Reyes Católicos. Repoblación, comercio, frontera, Granada, Universidad de Granada, vol. II, pp. 89-127.

-(1998): "Sobre las galeras venecianas de poniente y sus escalas ibéricas (siglo XV)", en Estudios en homenaje a Tomás Quesada, Granada, Universidad de Granada, pp. 401-416.

-(2001): "Granada y la ruta de poniente: el tráfico de frutos secos (siglos XIV-XV)", en MALPICA CUELLO, Antonio, (ed.), Navegación marítima del Mediterráneo al Atlántico, Granada, THARG., pp. 149-177. 
LÓPEZ PÉREZ, María Dolores (1995): La Corona de Aragón y el Magreb en el siglo XIV (1331-1410), Barcelona, CSIC.

MALPICA, Antonio (1999): “Il traffico commerciale nel mondo mediterraneo occidentale alla fine del Medioevo: il Regno di Granada", en ALBERINI, Paolo, (ed.), Aspetti ed attualità del potere marittimo in Mediterraneo nei secoli XII-XVI, Roma, Stabilimento Grafico Militare, pp. 351-381.

-(2002): "Sobre el mundo agrícola nazarí. La alquería de Escóznar en el siglo XIV", en REGLERO DE LA FUENTE, Carlos, (coord.), Poder y sociedad en la Baja Edad Media hispánica. Estudios en homenaje al profesor Luis Vicente Díaz Martín, Valladolid, Universidad de Valladolid.

—(2004): "El reino de Granada entre el Mediterráneo y el Atlántico", en ANATRA, Bruno, y MURGIA, Giovanni (eds.), Spagna e Mediterráneo. Dai Re Cattolici al Secolo d'Oro, Roma, Carocci, pp. 69-88.

-(en prensa): "La ciudad palatina de la Alhambra y el conjunto urbano de Granada", en Actas del Coloquio Al-Andalus: Un país de ciudades. Oropesa (Toledo), 1214 de mayo de 2005.

MALPICA, Antonio, y FÁBREGAS, Adela (2005): “Los genoveses en el reino de Granada y su papel en la estructura económica nazarí", en GALLINARI, Luciano, (ed.), Genova. Una "porta" del Mediterráneo, Cagliari, ISEM, CNR., vol. I, pp. 227-258.

MANCA, Ciro (1987): “L'Economia mercantile e marittima”, en MANCA, Ciro, (ed.), Formazione e trasformazione dei sistemi economici in Europa dal feudalesimo al capitalesimo, Padova, CEDAM, pp. 111-138.

MASI, Gino (1941): Statuti delle colonie fiorentine all'estero (sec. XV-XVI), Milano, Leo S. Olschki.

MELIS, Federigo (1976): "Malaga nel sistema economico del XIV e XV secolo", en Mercaderes italianos en España (siglos XIV-XV), Sevilla, Universidad de Sevilla, pp. 3-65.

MOLHO, Anthony, y RAMADA CURTO, Diogo (2003): “Les réseaux marchands à l'époque moderne", Annales. Histoire, Sciences Sociales, 58, pp. 569-579.

MURRAY, James M. (2005): Bruges, cradle of Capitalism, 1280-1390, Cambridge, Cambridge University Press.

PETTI BALBI, Giovanna (1996): Mercanti et nationes nelle Fiandre: $i$ genovesi in età bassomedievale, Pisa, G.I.S.E.M.

-(1997): "Le strategie mercantili di una grande casata genovese: Francesco Spinola tra Bruges e Malaga (1420-1456)", Serta Antiqua et Medievalia, 1, pp. 379-393.

PISTARINO, Geo (1987): "Génova medieval entre Oriente y Occidente", en AA. VV., El mundo mediterráneo en la Edad Media, Barcelona, Argot, pp. 191-228.

PISTARINO, Geo, y GARI, Blanca (1990): “Un trattato fra la repubblica di Genova e il regno moresco di Granada sulla fine del Quattrocento", La Storia dei genovesi, X, pp. 395-412. 
SALICRÚ, Roser (1997): “Génova y Castilla, genoveses y Granada. Política y comercio en el Mediterráneo occidental en la primera mitad del siglo XV (1431-1439)", en AIRALDI, Gabriella, (ed.), Le vie del Mediterraneo. Idee, uomini, oggetti (secoli XI-XVI), Génova, E.C.I.G., pp. 213-257.

-(1998): “La embajada de 1479 de Pietro Fieschi a Granada: nuevas sombras sobre la presencia genovesa en el sultanato nazarí en vísperas de la conquista castellana", Atti dell'Accademia Ligure di Scienze e Lettere, Serie V, LIV, pp. 255-385.

-(1999): "La Corona de Aragón y Génova en la Granada del siglo XV", en FERRER I MALLOL, María Teresa, y COULON, Damien, (eds.), L'expansió catalana a la Mediterrània a la Baixa Edat Mitjana, Barcelona, CSIC, pp. 121-144.

SÁNCHEZ MARTÍNEZ, Manuel (1988): “Mallorquines y genoveses en Almería durante el primer tercio del siglo XIV: el proceso contra Jaume Manfré (1334)", Miscel.lanea de Textos Medievals, IV, pp. 103-162.

SIMBULA, Pinuccia F. (2001): "Apertura de las rutas comerciales de las flotas italianas hacia el Atlántico", en MALPICA CUELLO, Antonio, (ed.), Navegación marítima del Mediterráneo al Atlántico, Granada, THARG, pp. 209-258.

SPUFFORD, Peter (2002): Power and profit. The merchant in medieval Europe, Londres, Thames \& Hudson.

TENENTI, Alberto, y VIVANTI, Corrado (1961): “Le film d'un grand système de navigation: les galères marchandes vénitiennes. XIVe-XVIe siècles", Annales, E.S.C., XVI, pp. 83-87.

VERLINDEN, Charles (1968): “Dal Mediterraneo all'Atlantico", en DEVOTO, Giacomo; VERLINDEN, Charles, y GIEYSZTOR, Alexander, Contributi per la storia economica, Prato, Istituto Internazionale di Storia Economica, pp. 29-51.

WATSON, Andrew M. (1998): Innovaciones en la agricultura en los primeros tiempos del mundo islámico, Granada, Universidad de Granada. 